\title{
Nesnelerin İnterneti Teknolojisinin Kümes Ortamına Uygulanması ve Etkileri
}

\author{
Yeliz Durgun \\ Tokat Gaziosmanpaşa Üniversitesi, Turhal Meslek Yüksekokulu, Elektronik ve Otomasyon Bölümü, Tokat,Türkiye, (ORCID: 0000-0003-3834-5533), \\ yeliz.durgun@gop.edu.tr
}

(1st International Conference on Applied Engineering and Natural Sciences ICAENS 2021, November 1-3, 2021)

(DOI: 10.31590/ejosat.1005685)

\begin{abstract}
ATIF/REFERENCE: Durgun, Y. (2021). Nesnelerin İnterneti Teknolojisinin Kümes Ortamına Uygulanması ve Etkileri. Avrupa Bilim ve Teknoloji Dergisi, (28), 463-468.
\end{abstract}

$\ddot{O} \mathbf{z}$

Son zamanlarda tarım alanında akıllı teknolojilerin kullanımı son derece yaygın bir hal almaya başlamıştır. Dünyada kanatlı hayvanlara olan talebin yükselmeye başlaması ile kümes hayvanı yetiştiriciliğinde de bir artışa yol açmıştır. Bu durum akıllı tarım sistemlerinde olduğu gibi teknolojik sistemlerle donatılmış kapalı kümes hayvancılı̆̆ınında da teknolojinin hızla gelişmesine yardımcı olmuştur. Kanatlı hayvancılık faaliyetleri için kümesler önemli alanlardır. Çünkü hayvanların yaşamsal faaliyetlerini sürdürebilmeleri için gerekli olan barınma ortamıdır. Kümes hayvanlarının optimal şekilde büyümesini sağlayabilmek için kümes içi parametreler olan sıcaklık ve nem miktarı muhafaza edilmelidir. Kümesteki havanın ve çevrenin kalitesi hayvanların hastalığa maruz kalmaması için korunmalıdır. Çünkü kapalı kümes ortamında amonyak mevcut olur. Bu gazlar tavukların hastalanıp ölümlerine yol açmaktadır. Bu ortam değişkenleri genellikle çiftçiler tarafından manuel olarak tahmin edilmektedir. Bu çalışmada kümes ortamının optimal koşullarının izlenmesini ve kontrolünü sağlayan Akıllı Tavuk Kümesi İzleme Sistemi geliştirilmesi amaçlanmıştır. Bu çalışmada, Nesnelerin İnternetine elektronik donanımlar NodeMCU mikro denetleyici kullanılarak tasarlanmıştır. Bulut sunucu için Linux işletim sistemine sahip konteyner yapısında yazılımlar kullanılmış ve geliştirilmiştir. Oluşturulan yapı sayesinde tavuk kümeslerinin izlenmesi ve destek sistemlerinin çiftçiler tarafından kolayca yapılabilmesi sağlanmıştır.

\section{The Application of the Internet of Things Technology to the Poultry Environment and Its Effects}

\begin{abstract}
Recently, the use of smart technologies in the field of agriculture has become extremely common. The increase in the demand for poultry in the world has led to an increase in poultry farming. This situation has helped the rapid development of technology in closed poultry farming equipped with technological systems, as well as in smart farming systems. Coops are important areas for poultry farming activities. Because it is the shelter environment that is necessary for animals to continue their vital activities. In order to ensure optimal growth of poultry, the indoor parameters of temperature and humidity must be maintained. The quality of the air and the environment in the house must be maintained so that the animals are not exposed to disease. Because ammonia is present in the closed house environment. These gases cause chickens to get sick and die. These environment variables are usually manually estimated by the farmers. In this study, it is aimed to develop an Intelligent Chicken Coop Monitoring System that monitors and controls the optimal conditions of the poultry house. In this study, electronic equipment for the Internet of Things is designed using NodeMCU microcontroller. For the cloud server, software in container structure with Linux operating system has been used and developed. Thanks to the structure created, it has been ensured that the monitoring of chicken coops and support systems can be made easily by the farmers.
\end{abstract}

Keywords: Smart Agriculture, Poultry Automation, Internet of Things, Tasmota, Home Assistant. 


\section{Giriş}

Dünyada ve ülkemizde taleplerin artış gösterdiği en hızlı büyüyen endüstriyel faaliyetlerden biriside kanatlı hayvan sektörüdür[1]. Artan nüfusa bağlı gıda talebi bu sektöre olan ilgi kümes hayvanı yetiştiriciliğinde de bir artışa yol açmıştır. $\mathrm{Bu}$ durum kümes hayvancılığında verimliliğin artırabilmek için çeşitli teknolojilerin kullanımını da beraberinde getirmektedir[2]. Kümeslerde hayvanların yaşamsal faaliyetlerini iyi bir şekilde sürdürebilmesi ve verimliliğini artırabilmesi için uygun koşullara sahip barınaklarının olması gerekmektedir[3]. Özellikle kümesler yazın güneşin zararlı ışınlarından ve fazla sıcaktan, kışın ise kar ve yağmurdan korunması için dizayn edilerek üretilmiş olmalıdır[4]. Oysa mevcut koşullarda var olan kümesler kendine özgü sorunlar barındırmaktadır. Bu kümeslerdeki sorunların başında, genellikle tavukların bulundukları kümeslerde ortam koşullarının optimum olmayan parametrelerden etkilenmesidir. Buna ek olarak kümeslerin bakımı konusundaki hatalar ve ihmallerde tavuk hastalıklarına hatta ölümlerine neden olmaktadır[5]. Kümes hayvan çiftliklerinde genellikle insan emeğiyle manuel olarak çiftlikler izlenmektedir. $\mathrm{Bu}$ durum ise çoğunlukla çiftliklerin doğru ve düzgün bir şekilde kontrol edilememesine sebep olmaktadır. $\mathrm{Bu}$ sebepten ötürüde kümes hayvancılığındaki verim istenilen düzeyde olmamaktadır.

Öte yandan da, tüketicilerin kanatlı hayvan ürünlerine olan talebinin artmasıyla çiftlikte optimum verimliliğe ulaşarak talebin istenilen oranlarda karşılanabilmesi için daha ileri teknolojilere ihtiyaç duyulmaktadır. Yeni nesil teknolojilerden nesnelerin birbiriyle iletişimi, sensörlerin kullanımıyla verilerin insan emeği olmadan dijital ortamda gerçek zamanlı olarak erişimleriyle kümes içinde optimum koşullar sağlanarak takiplerinin yapılması sağlanabilmektedir[6]. Nesnelerin interneti kümes hayvancığ 1 sektöründe de aktifleştikçe tavuk çiftliklerinde uygun yaşam alanları sağlanabilir bir hal alacağı için tavukları yaşam standartını artırılmasını sağlayacaktır[7]. Özellikle tavuk çiftliklerinde sıcaklık, nem, amonyak seviyeleri artış veya azalışı tavukları olumsuz etkilenmesine sebep olmaktadır[8]. Uygun olmayan sicaklık, tavukların üremesini desteklemez. Tavuk yetiştirme ortamındaki yüksek sıcaklıklar, tavukların büyümesini engelleyen 1sı stresine neden olabilir. Kümes sıcaklığının yanı sıra, tavuğun büyümesini büyük ölçüde etkileyen bir başka faktör de kümesin hava kalitesidir[9]. Havanın kalitesi içerisindeki gazların azlığı ve çokluğuyla belirlenebilir. Bir altlık tabanı ile karıştırılmış tavuk gübresinin fermantasyon süreci amonyak gazı (NH3) üretir. Tavuk tarafindan üretilen daha fazla gübre, daha fazla amonyak gazı üretir. Amonyak gazı oluşumu, altlığın veya gübrenin sıcaklık, nem, $\mathrm{PH}$ ve nitrojen içeriği gibi bazı faktörlerden etkilenecektir. Maruz kalma süresi ile birlikte amonyak konsantrasyonu hem tavuğun hem de çevredeki insanların sağlığını, özellikle de işçinin sağlığını etkileyecektir[10]. Kümeslerdeki tavukların bakımı, temizliği düzgün yapılmadığında insanlar ve çevre üzerinde olumsuz etki oluşturabilmektedir. Çünkü günlerce biriken tavuk gübresi miktarı, amonyak, nitratlar, nitritler ve hidrojen sülfit gazı gibi çeşitli gazlar üretecektir. Bu gazların varlığından tavuklar için üretkenliğin azalmasına ve ayrıca insanların solunum problemlerinden etkilenmesine neden olabilmektedir[11].Yapılan araştırma sonuçlarına göre kümes içindeki yüksek amonyak gazı seviyelerinin tavuğun yüksek ölüm oranlarına yol açabilecek hastalıklara karşı direncini etkilediği göstermektedir[12]. Ayrıca, kümes havasındaki yüksek amonyak konsantrasyonu yem alımını azaltır ve daha sonra büyüme hızını yavaşlatır, yumurta üretimini düşürür ve solunum fonksiyonunu azaltır. Bu faktörler, bir tavuk çiftliği işletmenin anahtarıdır. Bir tavuk çiftçisi sorunun üstesinden gelinebilirse, üretilen tavukların kalitesi ve miktarı artacaktır. Aynı zamanda kanatlı hayvancılıkta aydınlatmada tavukların gelişiminde önemli parametrelerden birisidir. Yapılan çalışmalarda 1şık yayan diyotların (LED) tavukların barınma yerleri olan kümeslerde yeterli miktarda 1şığ enerji tasarrufu yapılarak hem de tavukların üreme potansiyelini artırarak karkasta artışa sebep olduğu görülmüştür[13]. Çalışmamızda tavuk kümesindeki tavukların yaşamsal faaliyetlerini etkileyen çevresel parametreleri belirleyip bu durumların kontrolleri sağlanarak izlenmesini,takip edilmesini ve uzaktan gerçek zamanlı olarak kontrol edilmesini sağlayarak, tavuğun büyümesini, gelişmesini, bağ 1 şılığıını ve hayatta kalma oranını artırmasına katkıda bulunulması amaçlanmıştır.

\section{Materyal ve Metot}

\subsection{Sistem Yapısı}

Sistem bir aktuatör node (alt sistem A), bir sensör node sisteminden (alt sistem B), bir bulut docker konteynır sunucusu (alt sistem C) ve bir Android izleme yazılımından (alt sistem D) oluşur. A alt sistemi, otomatik aydınlatma ve fan kontrolünü sağlamak için kullanılır. B alt sistemi, kümes içerisindeki ortam sıcaklığg/nemi ve amonyak seviyesini izlemek için kullanılır. Alt sistem C, kümes ortamı izleme ve kontrolünün yapıldığg yazılım arayüzü ve alt sistem A ile alt sistem B'nin iletişim arayüzünü sağlamaktadır. Alt sistem D, kümes ortamının gerçek zamanlı gösterimi, kontrolü, depolanması ve veri görselleştirmesi için kullanılır. Geliştirilen alt sistem A için sıcaklık dedektörü olarak DHT 22 sensörünü ve amonyak gazı dedektörü olarak MQ-135 sensörleri tercih edilmektedir. Alt sistem B için ayrıca kümesin sıcaklığını ve nemini sabit tutmak için fan ile kontrol edebilmesini sağlanmıştır. Ek olarak iç aydınlatma kontrolüde sisteme dahil edilmiştir. Alt sistem C kısmında bulut sunucu üzerindeki Docker konteynır MQTT broker kullanılarak oluşturulmuştur. Diğer bir konteyner üzerine Homeassistant sistemi yüklenilerek kontrol ve izlem işlemleri yapılmasına olanak sağlanmıştır. Ayrıca alt sistem D sayesinde kullanıcısına bildirim ve kontrol için android mobil cihaz yazılımı üzerinden iletişim sağlanmıştır.

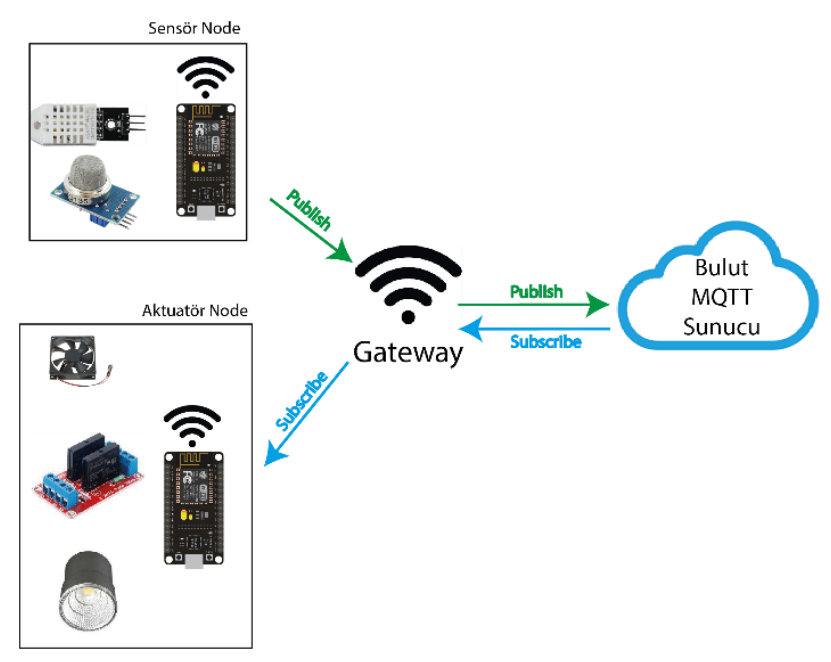

Şekil 1 Sistemin Yapısı 


\subsection{Donanım Bileşenleri}

NodeMCU : NodeMCU, açık kaynaklı bir nesnelerin interneti geliştirme platformudur. Yapısında bulunan ESP8266 kablosuz bütünleşik entegre devre (Wi-Fi System on Chip (SoC)) yapısındadır. Varsayılan olarak "NodeMCU" terimi, geliştirme kitleri yerine yazılımı ifade eder. Fakat biz bu yazılım yerine Tasmota Firmware yazılımı programlayarak IoT altyapısı haline getirilmiştir. Böylelikle çalışmalarımızı çok kolay ve nitelikli hale getirilmiştir[14].

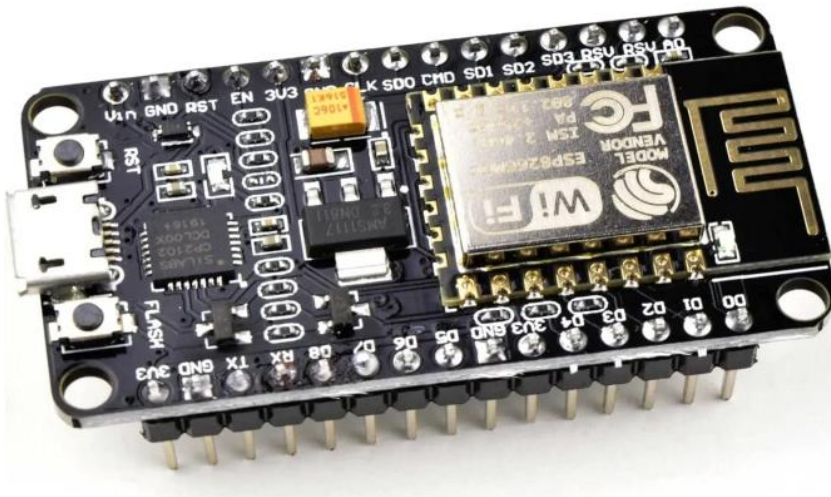

Şekil 2 NodeMCU platformu

Tasmota : ESP8266 Wi-Fi yapısını içeren yerel donanım yazılımı için Theo Arendts tarafindan oluşturulan NodeMCU cihazlarına MQTT ve OTA (Over The Air) sağlayan TASMOTA (Theo Arendts Sonoff-MQTT-OTA) adlı açık kaynaklı bir firmwaredir. Bu, her NodeMCU bileşeninin MQTT aracısına ve onunla ilişkili sanal bir cihaza veri göndermesine izin vermektedir. Şu an bu firmware ile, Python ile yazılmış ev otomasyonu için açık kaynaklı bir yazılım olan Home Assistant ile etkileşime girmesine izin verecek şekilde yapılandırılabilmektedir[15].

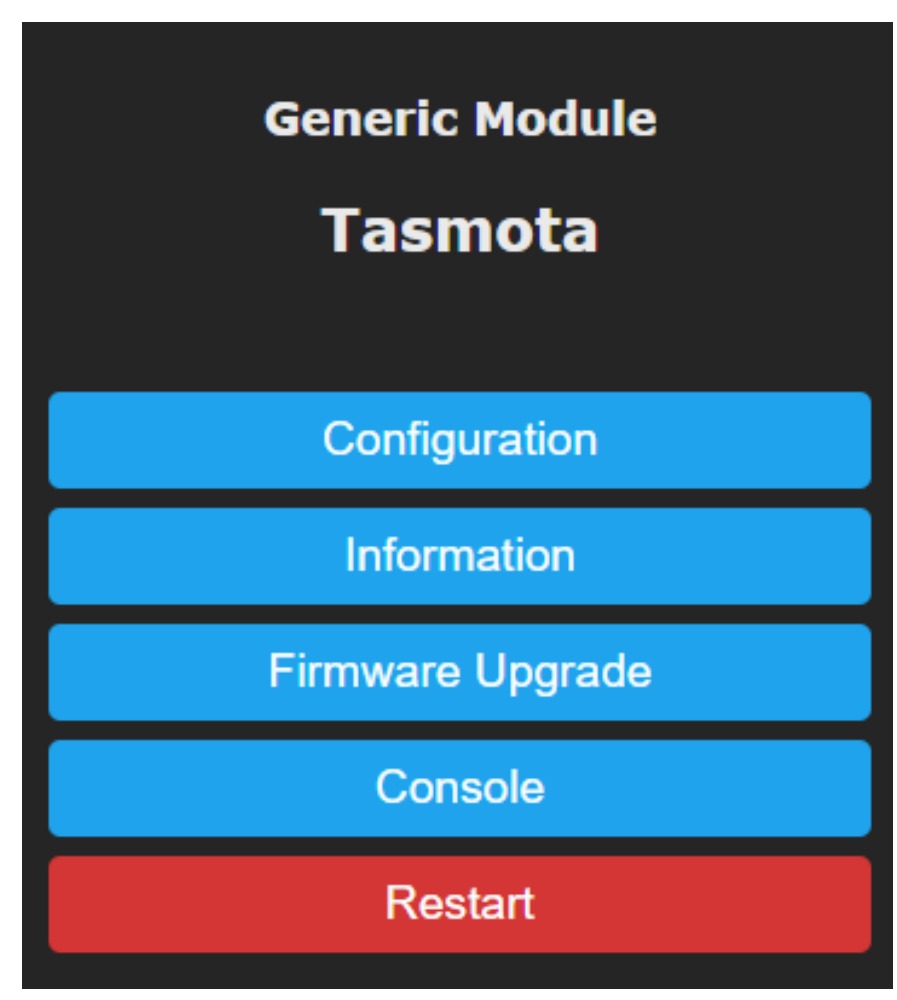

Şekil 3 Tasmota Kontrol Paneli
Home Assistant (HA) : HA (https://www.home-assistant.io), Python ile yazılmış Akıllı Evler için satıcıdan bağımsız bir açık kaynak çözümüdür. Hatta dağıtım yapmak için bir Docker konteyneri ile birlikte gelir. Çok sayıda açık kaynağın yanı sıra ticari cihazlarla kullanılabilir. Bir çok modül, protokol, servis ve yazılımı desteklemektedir. Home Assistant, bir MIT lisansı altında yayınlanmıştır[16].

Aktuatör Node : Aydınlatma ve Fan kontrolü için yapılmıştır. Fan ve Aydınlatma için röle modülü kullanılmıştır. Röle, elektrikle çalışan bir anahtardır. Aydınlatma için $220 \mathrm{~V}$ ile çalışan 3W led kullanılmıştır. Kümes içerisinde tavana yerleştirilmiştir. Fan olarak $220 \mathrm{~V}$ ile çalışan havalandırma fanı kullanılmıştır. Fan küme içerisinde duvara monte edilmiştir.

Sensör Node : Sicaklık, Nem ve Amonyak takibi için kullanılmıştır. Sıcaklık ve nemi izlemek için DHT22 sensörünü kullanıyoruz. DHT22 sensörü, bir mikro denetleyici kullanılarak daha fazla işlenebilen analog voltaj çıkışına sahip, sıcaklık ve nemi düzenleme işlevi gören bir sensördür. DHT22 modülü, algılama verilerinin kalitesini okuma açısından avantajları olan, sıcaklık ve nemi algılama açısından daha hızlı ve daha hızlı olan sıcaklık ölçüm cihazı gibi çekinik eleman olarak sınıflandırılan bir modüldür. Amonyak seviyesinin belirlenmesi için MQ-135 sensörü kullanılmıştır. Kombine bir gazı algılayan bir gaz sensörüdür. Bu hava kalitesi sensörü, bir güç bankası veya pil aracılığıyla 5 volt ile çalışmaktadır. MQ-135, mikro boyutlu seramik tüp malzemesi (Al2O3), hassas bir Tindioxid tabakas1 (SnO2), plastik ve çelik dokudan yapılmış kabuk üzerinde sabit bir elektrot ve 1sitma ölçüm sistemi ile yapılmış bir gaz sensörüdür. Bu 1sıtıcı, hassas bileşenler üzerinde belirli koşullara göre görev yapar. MQ-135 direnç değeri, gaz konsantrasyonundaki değişikliklerle farklıdır. $\mathrm{Bu}$ sensör bileşenini kullanırken hassasiyet kalibrasyonu gerektirir.

Bulut Sunucu : Linux işletim sistemine sahiptir. Linux üzerine Docker kontey0ner yapısında bulut sunucu oluşturulmuştur. Konteyner yapısı uygulama oluşturma, devreye alma ve yönetmeye yönelik açık kaynak kodlu bir platformdur. İçerisine MQTT protokolü için MQTT broker konteynerı kullanılmıştır. Ek olarak sunucuya Home assistant'ta ayrı bir konteyner olarak yüklenmiştir.

\subsection{Deney Düzeneği}

Şekil 4'de gösterildiği gibi kümes boyutları yaklaşık $3 \mathrm{mt} \mathrm{x}$ $3 \mathrm{mt}$ genişliğinde ve $2 \mathrm{mt}$ yüksekliğinde tuğla ile örülü kümes kullanılmıştır. Kümes içerisinde yumurtlama için folluklar, tüneme alanları, havalandırma penceresi ve tabanlık gibi eşyalar bulunmaktadır. Yaklaşık 15 adet tavuk barınmaktadır. 


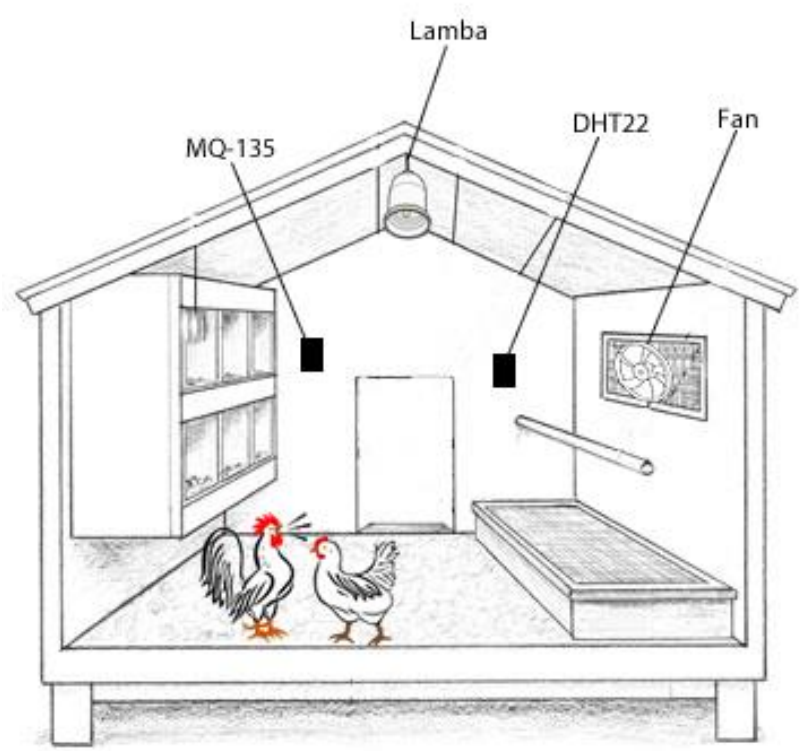

Şekil 4 Kümes düzeneği

\section{Bulgular}

Sistem geliştirildikten sonra kümes kurulumu Tokat Turhal ilçesinde bulunan gezen tavuk yetiştiriciliği yapılan bir tesis üzerinde test edilmiştir. Deney, 01 Ekim 2021'de yapılan ölçümler ve uygulamalar sonuçlarda gösterilmiştir.

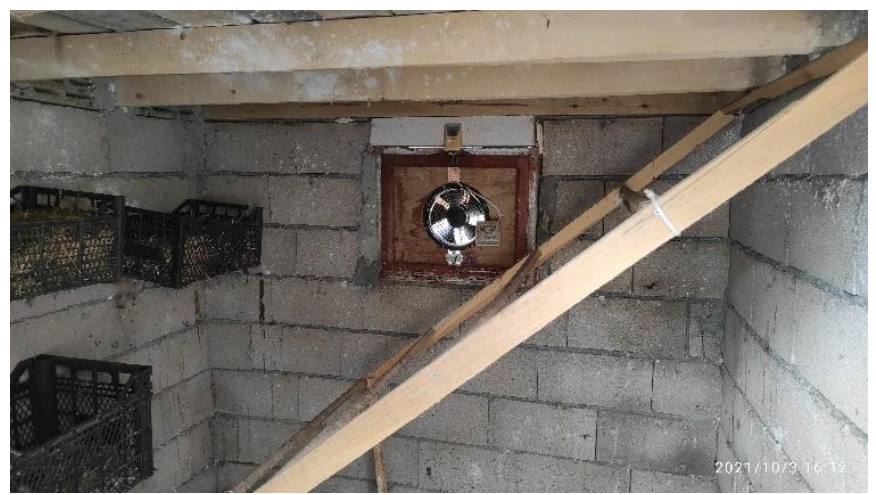

Şekil 5 Uygulama yapılan kümes

DHT 22 ile yapılan ölçümler yaklaşık 10 sn aralıklarla sunucu üzerine aktarılmıştır. Sıcaklık ölçüme ait sonuçlar şekil 6'da gösterilmektedir. Şekil 6' da görüldüğü gibi 13:00 ile 15:00 aralığında fan açıp kapatma işlemleri yapılarak sıcaklık değişimi sağlanmıştır. Bu işlem sonucunda grafikte görüleceği gibi testere şeklinde olmuştur.
(

DHT22 Temperature

In 10 seconds

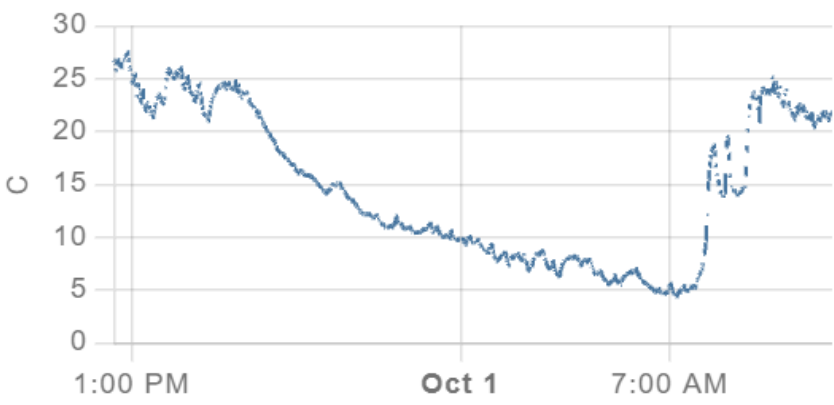

Şekil 6 Sıcaklık verilerine ait çizgi grafiği

Şekil 7'de Kümes içerisi nem değerleri gösterilmektedir. Nem değerleri şekilde görüldüğü gibi 18:00 de hayvanların kümes içerisine girmesiyle nem değerleri yükseldiği, Gün aydınlaması 07:00 ile birlikte hayvanların kümes içerisinden ayrılmasıyla nem değerlerinin azaldığı görülmektedir.

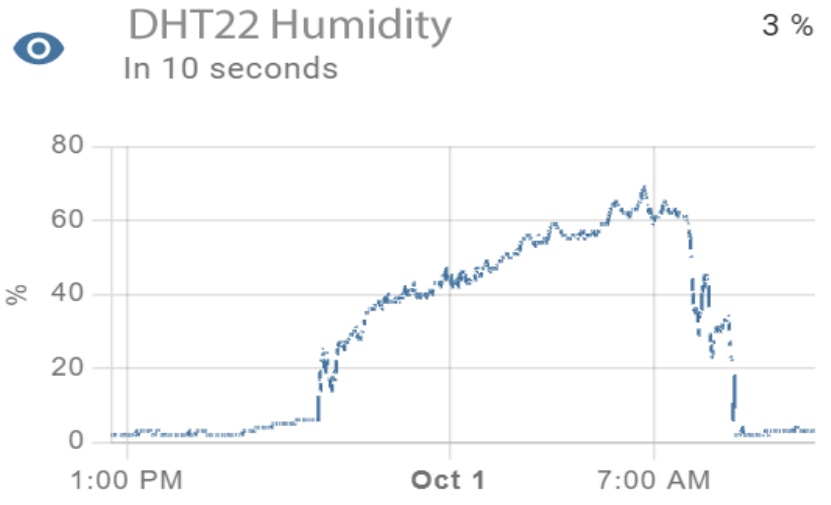

Şekil 7 Nem verilerine ait çizgi grafiği

Şekil 8'de MQ-135 sensörüne ait amonyak değerlerinin ölçümleri gösterilmektedir. Kümes ölçümler ppm olarak ölçülmüştür. Ölçülen değerlerde 25 ppm max değer olarak alınmıştır. $\mathrm{Bu}$ değere ulaştığında kullanıcıya bildirim göndermektedir. Ayrıca fan açılarak içerinin havalandırılması sağlanmıştır. Ortalama amonyak seviyemiz 10 ppm olarak hesaplanmıştır.
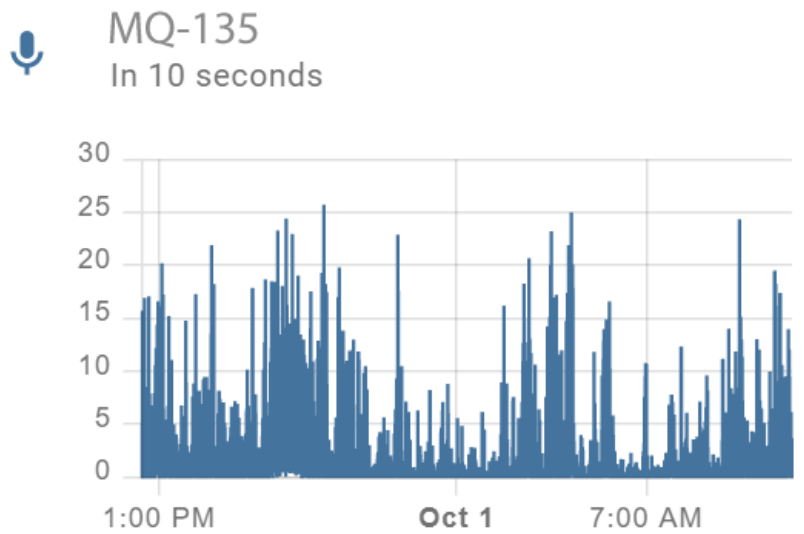

Şekil 8 MQ-135 gaz verilerine ait çizgi grafiği 
Şekil 9'da kümes içi aydınlatma için kullanılan led kontrol butonu ve 1şık miktarı ayarlayacağı gösterilmektedir. Bu sayede 1şık kümes içerisinde ne kadar verilmek isteniyorsa o kadar verilebilmektedir. Işsı miktarı 0 ile 100 birim aralığında ayarlanabilmektedir.

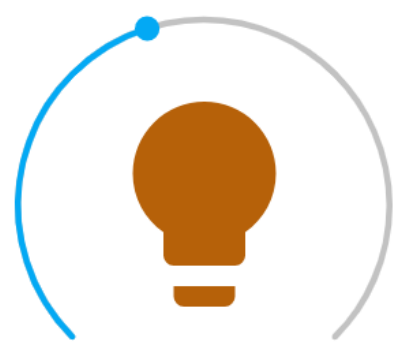

lamba

\section{Şekil 9 İç aydınlatma kontrol arayüzü}

Şekil 10'da Fan için kullanılan röle devresi kontrolü için arayüz butonları gösterilmektedir. Buton açık ve kapalı durumlarına göre geri bildirimli olarak çalışmaktadır. Role2_1 nolu çıkışa fan bağlanmıştır. Diğer Röle çıkışı kullanılmamıştır.

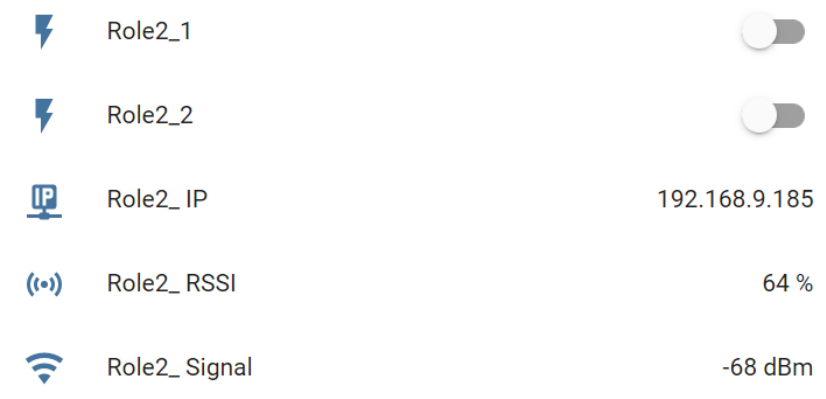

Şekil 10 Fan kontrol arayüz butonları

\section{Tartışma}

Yapılan çalışmada, kümes içerisinde yerleştirilen sensörler aracılı̆̆ıgla kümes içi sıcaklığı nemi ve ortam gaz miktarını sensör ağından elde edilen verilerin nesnelerin interneti teknolojisinde kullanarak yorumlayarak ideal ölçüde kullanılması hedeflenmiştir. Amaç ortamın hava kalitesini kontrol etmek ve sıcaklıklığın nemin izlenerek ideal koşulların dışına çıkıldığında fan gibi gerekli sistemlerin nesnelerin interneti teknolojisini kullanarak devreye girmesidir. Bu doğrultuda çalışmanın ilk çıktısı olarak akıllı kümes izleme sisteminin kontrol merkezi olan destekli gömülü sistemin tasarımı gerçekleştirilmiştir. Çalışmanın bu aşamasında laboratuvar ortamında geliştirilen gömülü sistemin çalışması test edilmiştir. Bu çalışmada ki bulgular gösterilmiştir; fakat bu sonuçların yapay zekâ desteği ile belirlenmesi sisteme dahil edilmesi planlamaktadır. Sadece sistemin birlikte çalışabilirliği, sürekliliği ve hata oluşmama durumları test edilmiştir. Şekil 6-7-8'de görüleceği üzere hatalı, fazla ve yanlış ölçüm gibi değerler bulunmamaktadır. Devre elemanlarında çalışmama veya veri eksikliği tespit edilmemiştir. Bunun sonucunda sistemin kararlı bir biçimde çalıştı̆ı gösterilmiştir.
Tavuk kümesindeki ortam değişkenleri olan sıcaklık, nem ve amonyak miktarı sensörler aracıllğı ile veriler elde edilmiştir. Bunun yanı sıra gerçek zamanlı olarak 1sıtma cihazları, nemlendirme cihazları ve havalandırma cihazlarıda kontrol edilebilmesi gelecekte yapılabilecektir. Kablosuz ağ topolojisi oluşturularak tüm birimleri birbirine bağlaması yardımcı olunacaktır. $\mathrm{Bu}$ durum ise kablolama seviyesini en aza indirilecektir. Oluşturulan bulut yapı sayesinde hem sensörler hem de cihazlar kendi aralarında haberleşerek gelen veri ile kümes içi hava kalitesinin ölçülmesi ve izlenmesi gerçekleş̧irilmiştir. Aynı zamanda nesnelerin interneti yardımıyla sıcaklık, nem, miktarları takip edilerek sıcaklığın nemin arttığı durumlarda fan sistemleri devreye girmiştir.

$\mathrm{Bu}$ aşamadan itibaren ölçüm değerlerine veya belirlenen aralığa göre aktuatörlerin aktifleşmesine alternatif olarak yapay zeka algoritmalarıyla çalıştııılması planlanmaktadır. Bununla birlikte alınan çok miktarda verilerin değerlendirilerek yine yapay zeka yardımı ile anlamlı veri haline getirilmesi planlanmaktadır.

\section{Sonuçlar}

Kümes hayvan yetiştiricilerin sorun olarak gördüğü ve çözümlenmesi istediği dört temel problem mevcuttur. $\mathrm{Bu}$ problemler için çözümler geliştirilmiştir. İlk olarak kümes ortamının sıcaklık ve neminin anlık olarak ölçümlerini takip edebilen sistem geliştirilmiştir. Bu sistemde yer alan sensörlerle düzenli olarak ortamın sıcaklığı ve nemi kontrol edilmiştir. Böylece iyi çalışan bir sistem oluşturulmuştur. İkinci olarak bu sıcaklık ve nem parametrelerini kontrol eden bir düzenli sistem ve fan sistemi geliştirilmiştir. Böylece kümes hayvanları sahipleri her an gerçek zamanlı olarak kümesin sıcaklık ve nemi uzaktan izleyebilecektir. Uygun olmayan sicak ortam veya nemli koşullarda sistemde fan otomatik olarak çalışarak ortamın nemini ve sıcaklığını ideal koşullarda tutulması sağlanmıştır. Dolayısıyla kullandığımız tüm sensör ve fanlar iyi bir şekilde çalışmıştır. Üçüncü olarak öncesinde kümes hayvan sahipleri sıcaklığın ve nemin kontrolünü sağlayabilmek için çok sayıda işçi kullanmaktaydı. Bu sistem sayesinde çiftçiler, tüm süreçleri kendileri otomatik olarak kontrol edilebildiği için işçi kullanımını azaltabilecektir. Son olarak nesnelerin internetini kullanarak sıcaklık, nem ve ortamdaki gazları izleyebilen bir sistem oluşturabilmiş̧ir. Bu projede akıllı ev otomasyon sistemi olan Home assistan platformuna kümes kontrol işlemleri ilk kez eklenmiş̧ir. Bu platformun kullanımı ile kümes hayvan sahipleri, nerede olurlarsa olsunlar, Akıllı Telefonlar veya Kişisel bilgisayarlar gibi cihazlar aracılığıyla tüm okumaları izleyebilecek ve kontrol edebileceklerdir. Yaptığımız çalışmada nesnelerin internetini kullanarak tavuk kümeslerinin hava kalitesini izlenmesine olanak sağlayarak yenilikçi bir çözüm sunulmuştur. Nesnelerin interneti tabanlı mikrodenetleyicideki teknolojik gelişmeler internet üzerinden iletişimde kolaylık sağlayacaktır. Çalışmada kullanılan bu teknoloji, internet bağlantısına bağlı olduğu sürece her zaman ve her yerde kontrol edilebilecektir 


\section{Kaynakça}

[1] P. O. Ayoola, "Development of A Policy Framework for the Growth of Biogas Technology using Poultry Droppings", Int . J. Eng. Res. And, V9, c. 3, ss. 314-319, 2020.

[2] G. Corkery, S. Ward, C. Kenny, ve P. Hemmingway, "Incorporating Smart Sensing Technologies into the Poultry Industry", J. World's Poult. Res., c. 3, say1 4, ss. 106-128, 2013.

[3] Y. Liani, I. Munthe, ... D. I.-2021 3rd, ve undefined 2021, "The Broiler Chicken Coop Temperature Monitoring Use Fuzzy Logic and LoRAWAN", ieeexplore.ieee.org.

[4] R. Ramadiani, D. Widada, M. Widiastuti, ve M. Jundillah, "Temperature and humidity control system for broiler chicken coops", Indones. J. Electr. Eng. Comput. Sci., c. 22, say1 3, ss. 1327-1333, 2021.

[5] D. E.-G. Bellolio, C. Davis, ve M. Ely, "Chicken Coop Cleaner Prototype:'Pooper-Picker-Upper”, 2021.

[6] P. Adinegoro, M. H. Habbani, R. A. Karimah, ve Y. A. Laksono, "The Design of A Telegram IoT-based Chicken Coop Monitoring and Controlling System", JPSE (Journal Phys. Sci. Eng., c. 5, say1 2, ss. 56-65, 2020.

[7] R. D. M. Nicolas, W. S. Zhou, S. C. Kitamura, ve M. J. C. Samonte, "An IoT Monitoring Assistant for Chicken Layer Farms", içinde 2019 International Conference on Information and Communication Technology Convergence (ICTC), 2019, ss. 71-75.

[8] A. A. Swelum $v d$., "Ammonia emissions in poultry houses and microbial nitrification as a promising reduction strategy", Sci. Total Environ., s. 146978, 2021.

[9] H. Supriyono, U. Bimantoro, ve K. Harismah, "Design, Construction and Testing of Portable Systems for Temperature, Humidity and Ammonia Monitoring of Chicken Coop", içinde IOP Conference Series: Materials Science and Engineering, 2020, c. 771, sayı 1.

[10]H. H. Kristensen ve C. M. Wathes, "Ammonia and poultry welfare: a review", Worlds. Poult. Sci. J., c. 56, say1 3, ss. 235-245, 2000.

[11]K. J. Donham, D. Cumro, S. J. Reynolds, ve J. A. Merchant, "Dose-response relationships between occupational aerosol exposures and cross-shift declines of lung function in poultry workers:: recommendations for exposure limits", J. Осcup. Environ. Med., c. 42, say1 3, ss. 260-269, 2000.

[12]P. Bhadauria, J. M. Kataria, S. Majumdar, ve S. K. Bhanja, "Impact of hot climate on poultry production system-a review", 2014.

[13]J. C. Huth ve G. S. Archer, "Comparison of two LED light bulbs to a dimmable CFL and their effects on broiler chicken growth, stress, and fear", Poult. Sci., c. 94, say1 9, ss. $2027-$ 2036, 2015.

[14] U. Ozkaya, Ş. Öztürk, K. Tuna, L. Seyfi ve B. Akdemir, "Faults Detection With Image Processing Methods In Textile Sector", içinde 2018 1st International Symposium on Innovative Approaches in Scientific Studies.

[15]"News - Tasmota". [Çevrimiçi]. Available at: https://tasmota.github.io/docs/. [Erişim: 04-Eki-2021].
[16]"Home Assistant”. [Çevrimiçi]. Available at: https://www.home-assistant.io/. [Erişim: 21-Mar-2021]. 